\title{
High resolution simulations of a flash flood near Venice
}

 \\ ${ }^{1}$ Institute of Atmospheric Sciences and Climate, ISAC - CNR, Bologna, Italy \\ ${ }^{2}$ Department of Environmental Sciences, Parthenope University of Naples, Naples, Italy \\ ${ }^{3}$ Institute of Atmospheric Sciences and Climate, ISAC - CNR, Padua, Italy
}

Received: 1 April 2009 - Revised: 2 September 2009 - Accepted: 21 September 2009 - Published: 9 October 2009

\begin{abstract}
During the MAP D-PHASE (Mesoscale Alpine Programme, Demonstration of Probabilistic Hydrological and Atmospheric Simulation of flood Events in the Alpine region) Operational Period (DOP, 1 June-30 November 2007) the most intense precipitation event observed south of the Alps occurred over the Venice Lagoon. In the early morning of 26 September 2007, a mesoscale convective system formed in an area of convergence between a south-easterly low level jet flowing along the Adriatic Sea and a northeasterly barrier-type wind south of the Alps, and was responsible for precipitation exceeding $320 \mathrm{~mm}$ in less than $12 \mathrm{~h}$, $240 \mathrm{~mm}$ of which in only $3 \mathrm{~h}$.

The forecast rainfall fields, provided by several convection resolving models operated daily for the D-PHASE project, have been compared. An analysis of different aspects of the event, such as the relevant mechanisms leading to the flood, the main characteristics of the MCS, and an estimation of the predictability of the episode, has been performed using a number of high resolution, convection resolving models (MOLOCH, WRF and MM5).

Strong sensitivity to initial and boundary conditions and to model parameterization schemes has been found. Although low predictability is expected due to the convective nature of rainfall, the forecasts made more than $24 \mathrm{~h}$ in advance indicate that the larger scale environment driving the dynamics of this event played an important role in favouring the achievement of a relatively good accuracy in the precipitation forecasts.
\end{abstract}

\section{Introduction}

Heavy precipitation events have a strong impact on human activities. In order to limit the risks associated with precipitation and flooding, reliable quantitative precipitation forecasts

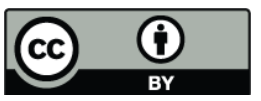

Correspondence to: S. Davolio (s.davolio@isac.cnr.it)
(QPF) are required. However, forecasting heavy rainfall, especially when associated with deep moist convection, is still a major challenge for numerical weather prediction (NWP) systems, since it requires an adequate simulation of many processes acting on different scales and of their complex interactions, whose knowledge and modelling is far from being accurate. Moreover, moist convection is an intrinsic source of forecast uncertainty, therefore limiting predictability of heavy precipitation events, even if we assume having a perfect model and a perfectly predictable large scale situation (Hohenegger and Schär, 2007). Therefore, despite the remarkable improvements obtained in the last years, NWP models, even at high horizontal resolution and short forecast times, are usually not yet able to predict timing, spatial location and intensity of precipitation (Anquetin et al., 2005; Richard et al., 2007) with satisfactory accuracy.

The MAP D-PHASE project aimed at demonstrating a clear advance in forecasting capability over complex terrain. The emphasis was put on high resolution operational modelling, be it probabilistic or deterministic (Rotach et al., 2009). The D-PHASE provided, for the first time in Europe, the opportunity of having access to real time, very high resolution forecasts issued by a number of different convection resolving models, operated both by meteorological services and research institutions. The very intense precipitation event that affected an area near Venice on 26 September 2007 represents an interesting case study: it allows to evaluate the ability of state-of-the-art convection resolving models to forecast the mesoscale phenomena that determine location and timing of thunderstorm activity and thus to evaluate if organized convection can be predicted in the short range by different models. In this context, after a description of the meteorological situation presented in Sect. 2, QPF of four high resolution models, operational during the project, are compared in Sect. 3. Further experiments are discussed (Sects. 4 and 5) in order to provide a deeper insight into the main mesoscale features responsible for the occurrence of heavy rain. 



Fig. 1. (a) Observed accumulated precipitation (mm) from 00:00 to $12: 00$ UTC, 26 September 2007, obtained by interpolating rainfall data from 43 weather stations (indicated by the dots). Rainfall analysis was generated using the Cressman interpolation technique (Daley, 1991) implemented in the GrADS graphical package (Grid Analysis and Display System, http://www.iges.org). Gray shading indicates orography. (b) MSG satellite VIS image at 06:00 UTC, 26 September 2007 (courtesy of LAMMA, EUMETSAT copyright).

\section{The event}

During the Operational Period of the project, the most intense precipitation event south of the Alps occurred over a flat area near Venice in the early morning of 26 September, producing a local severe flood in the nearby towns of Marghera and Mestre.

A mesoscale convective system (MCS) formed west of the Venice Lagoon producing precipitation in excess of $320 \mathrm{~mm}$ in less than $12 \mathrm{~h}$ (Fig. 1a), of which more than $240 \mathrm{~mm}$ fell in



(b)

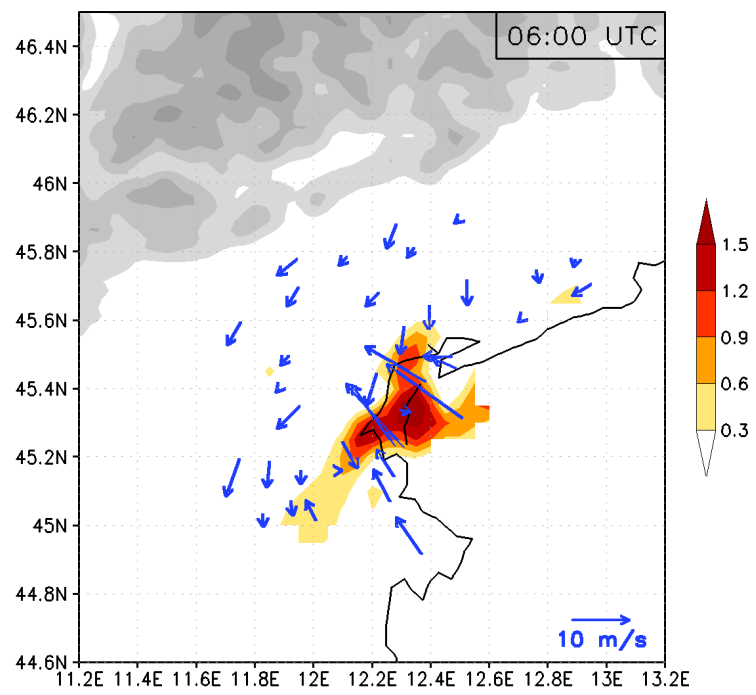

Fig. 2. (a) ECMWF analysis of 10-m wind field (m/s) at 06:00 UTC, 26 September 2007; (b) wind observations and convergence $\left(\mathrm{s}^{-1}\right.$, colour shading) from 37 weather stations over the Veneto Region, for the same time. Convergence was computed on the observed wind field obtained by interpolation of the available data. Interpolation was performed as for the rainfall fields (see caption of Fig. 1). Gray shading indicates orography.

only three hours. Rain rates locally exceeded $100 \mathrm{~mm} / \mathrm{h}$. The MCS developed in an area of convergence between a southeasterly low level jet (LLJ), flowing along the Adriatic Sea, and a north-easterly "barrier-type" wind south of the Alps. Later in the morning of 26 September, a colder airflow crossing the Eastern Alps merged with this barrier flow (Fig. 2a), reinforcing the north-easterly wind over the Veneto region. Such mesoscale circulation patterns were associated with a mid-tropospheric trough that, deepening while approaching the western Alpine region, favoured the development of 


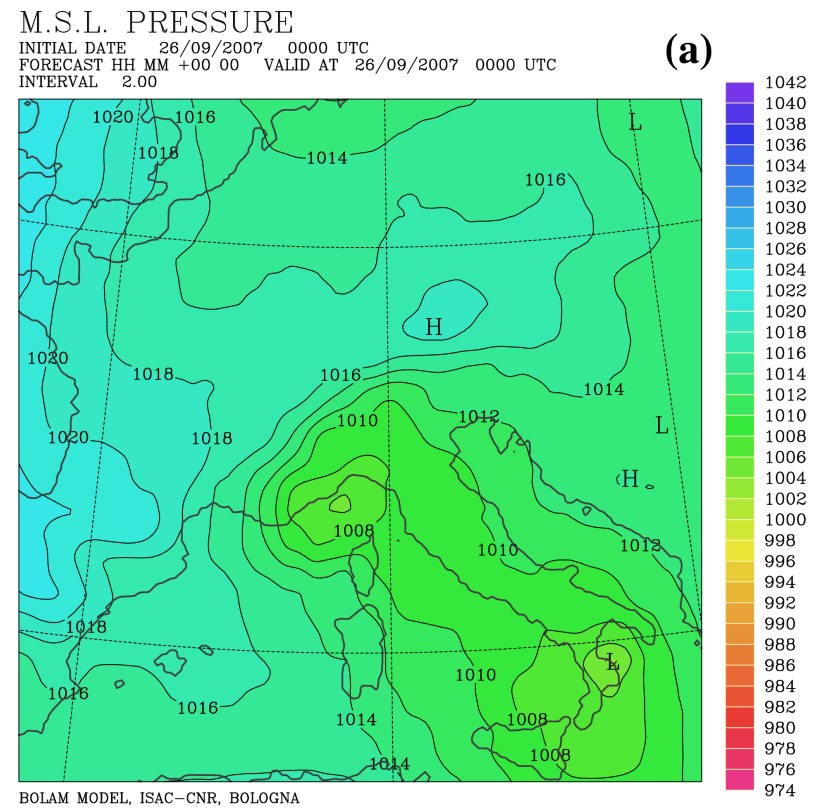

GPH AT 500 HPA

INITAL DATE $26 / 09 / 2007$ o000 UTC
FORECAST HH MM
INTERVAL 30.0 +00 00 VALID AT 26/09/2007 0000 UTC

(b)

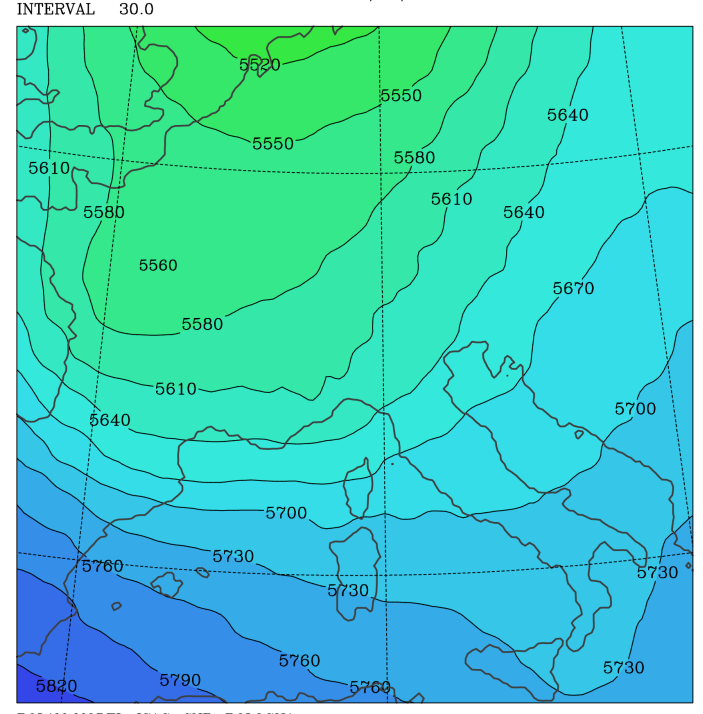

BOLAM MODEL, ISAC-CNR, BOLOGNA

Fig. 3. GFS-NCEP analysis fields for 00:00 UTC, 26 September 2007. (a) mean sea level pressure $(\mathrm{hPa})$; (b) geopotential height (gpm) at $500 \mathrm{hPa}$.

a moderate mesoscale orographic cyclone centred over the Gulf of Genoa (Fig. 3a and b). The orographic cyclone contributed to enhance the south-easterly flow over the Adriatic Sea, responsible for advecting moist and unstable air towards the eastern Po Valley.

The occurrence of a long lasting MCS associated with the convergence among a moist south-easterly flow from the sea, an orographically-induced current from the north-east and a westerly flow has been found in a similar episode of deep convection and severe flooding affecting the Montserrat area in Catalunya (Zampieri et al., 2005). In that case, known as the "Montserrat-2000 event", the orographically modified mesoscale flow was induced by the Pyrenees and converged with a warm and moist LLJ that developed over the Western Mediterranean.

Different scattered convective cells formed in the area located between the Veneto Alps and the Venice Lagoon, starting around 02:00 UTC, 26 September. Deep convection developed 2-3 h later into a MCS that formed about $20 \mathrm{~km}$ to the west of Venice and insisted over the same region for more than $6 \mathrm{~h}$. The surface wind configuration and related convergence zone persisted throughout the MCS activity (Fig. 2a and b), suggesting that the moist south-easterly flow played an important role in feeding the convection. Finally, the MCS moved slowly to the east, over the Adriatic Sea. The MCS was characterized by a distinct V-shaped cloud top (Fig. 1b), oriented SW-NE, and was quite deep (top temperature about $-55^{\circ} \mathrm{C}$, corresponding to a height of about $12 \mathrm{~km}$ ).

\section{High resolution operational model results}

Different high resolution forecasts were compared and analysed for this event in terms of accumulated rainfall and of the main aspects of the mesoscale circulation responsible for the development of the convective system. Among all the operational convection resolving models available during the D-DPHASE, only three suitably covered the area of interest, namely AROME (Bouttier and Roulet, 2008), COSMO_CH (www.cosmo-model.org) and MOLOCH (Malguzzi et al., 2006). The latter was run with two different set up, using independent initial conditions. Both MOLOCH runs were nested in BOLAM (Zampieri et al., 2005), so that a total of four forecasts is analysed in this section. Operational data assimilation was implemented in AROME (3D-Var scheme; Fischer et al., 2005) and COSMO_CH (nudging of SYNOP, surface observations and radiosonde data; Schraff, 1997). The main characteristics of model set up are summarized in Table 1.

Precipitation fields, predicted by the different models over the time interval from 00:00 to 12:00 UTC, 26 September (Fig. 4a), were analysed and compared with the corresponding observed rainfall. Observed precipitation was obtained by interpolating rainfall data from 43 weather stations of a quite dense network (on average, the weather stations are $20 \mathrm{~km}$ apart) managed by ARPA Veneto, Comune di Venezia and ISMAR-CNR (see locations in Fig. 1a).

AROME forecast produced a distinct portion of precipitation over the Adriatic Sea with a maximum of about $160 \mathrm{~mm}$. The northernmost precipitation peak, of about $140 \mathrm{~mm}$, was modelled over the coastal area adjacent to the eastern tip of the Venice Lagoon. COSMO_CH model gave the smallest precipitation amount among the selected models. Some scattered peaks of about $40 \mathrm{~mm}$ (not shown) were simulated over 
Table 1. Main characteristics of D-PHASE models configuration. The coupling among the corresponding coarse and fine resolution models is performed through one-way nesting.

\begin{tabular}{llllll}
\hline $\begin{array}{l}\text { High Resolution } \\
\text { Model }\end{array}$ & $\begin{array}{l}\text { Resolution } \\
(\mathrm{km})\end{array}$ & $\begin{array}{l}\text { Initial time } \\
(\mathrm{UTC})[\mathrm{h}]\end{array}$ & $\begin{array}{l}\text { Forecast } \\
\text { range }[\mathrm{h}]\end{array}$ & $\begin{array}{l}\text { IC/BC } \\
(\text { run })\end{array}$ & $\begin{array}{l}\text { DRIVING GLOBAL } \\
\text { MODEL }\end{array}$ \\
\hline AROME & 2.5 & $00: 00,26 \mathrm{Sep}$ & 30 & ALADFR & ARPEGE (00:00, 26 Sep) \\
COSMO_CH & 2.2 & $00: 00,26 \mathrm{Sep}$ & 24 & COSMOCH7 & ECMWF (00:00, 26 Sep) \\
MOLOCH_GFS & 2.2 & $09: 00,25 \mathrm{Sep}$ & 39 & BOLAM & GFS (00:00, 25 Sep) \\
MOLOCH_EC & 2.2 & $00: 00,26 \mathrm{Sep}$ & 48 & BOLAM & ECMWF (18:00, 25 Sep) \\
\hline
\end{tabular}

the coastal area east of the Lagoon. The most intense precipitation was located over and at the foothills of the Alps, northwest of the focus area, with a peak of about $80 \mathrm{~mm}$. MOLOCH_EC run showed a precipitation pattern covering the region extending from the Lagoon area to the Alps. The precipitation maximum was located over the flat region in between the two areas, with a maximum of about $150 \mathrm{~mm}$. Rainfall up to $120 \mathrm{~mm}$ was reproduced over the area where the most intense precipitation was observed, while weak rainfall was predicted over the sea. MOLOCH_GFS run provided the highest and most realistic precipitation among the four forecasts. Intense precipitation was produced over the sea facing the area of interest and the adjacent flat region: a maximum of about $240 \mathrm{~mm}$ was located close to the observed one. In the same forecast, a wide area of intense simulated precipitation also affected the mountainous region with a secondary maximum of $180 \mathrm{~mm}$ in $12 \mathrm{~h}$. The latter corresponded to an observed rainfall maximum, although remarkably weaker (about $50 \mathrm{~mm}$ ).

Figure $4 \mathrm{~b}$ shows the hourly observed and forecast precipitation rates averaged over an area of $1^{\circ} \times 1^{\circ}$ (shown in Fig. 4a) surrounding the observed precipitation maximum northwest of Venice. Observations were interpolated using hourly data available in the area. It can be seen that all the models except COSMO_CH reproduced a distinct rainy phase starting and culminating during the first $12 \mathrm{~h}$ of 26 September. The timing of the rainfall peak was captured best by AROME (initialized at 00:00 UTC of 26 September 2007), while it was affected by a delay of about $3 \mathrm{~h}$ in MOLOCH_GFS (nested in BOLAM, which was driven by the GFS forecast from 25 September at 00:00 UTC). The maximum hourly intensity was underestimated by AROME and overestimated by MOLOCH_GFS. The MOLOCH_EC run (nested in BOLAM, which was initialized from the ECMWF forecast from 25 September at 18:00 UTC) still produced intense convection over the same area, but with a less realistic time evolution.

The largest amounts of precipitation in all the four runs extended along a direction roughly from southeast to northwest, that is from the coastal to the mountainous region, indicating the occurrence of two different lifting mechanisms, due to low-level convergence zones over the flat terrain and over the sea, and to orography near the Alps. The time evolution
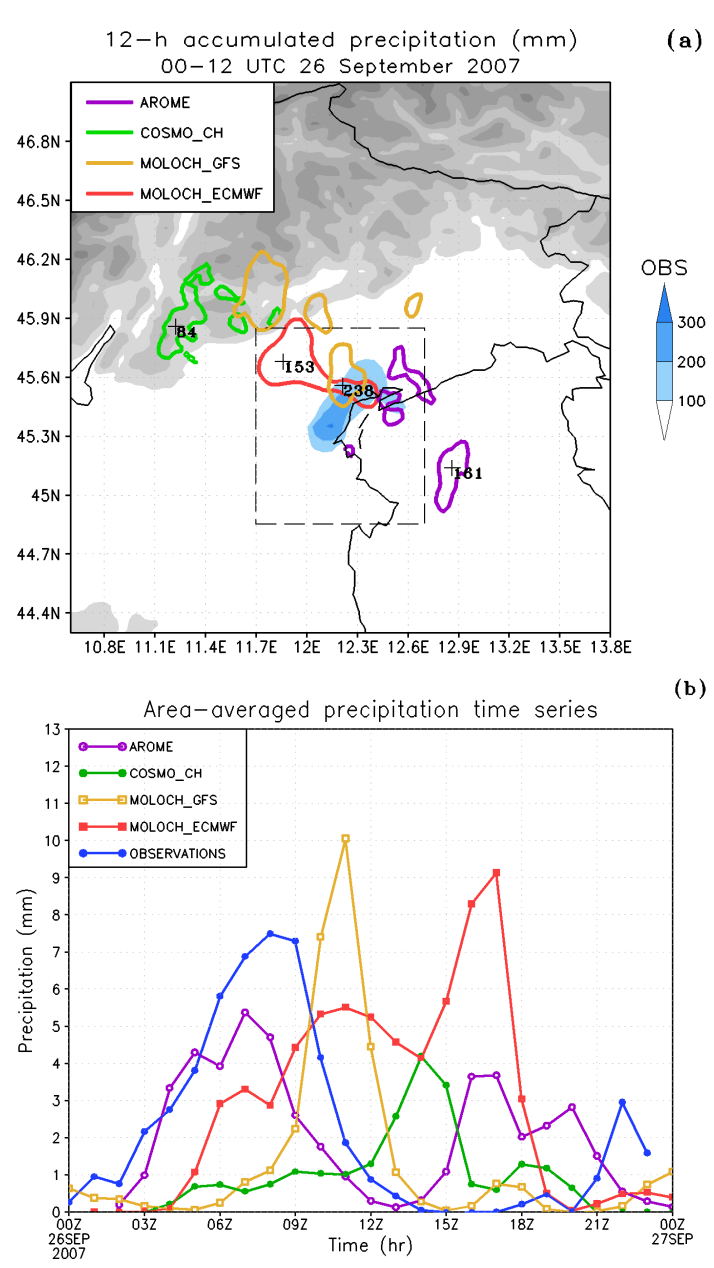

Fig. 4. (a) Observed (blue shading) and forecast accumulated precipitation (mm) from 00:00 to 12:00 UTC, 26 September 2007. 100$\mathrm{mm}$ isoline is drawn for AROME, and MOLOCH forecasts, $50-\mathrm{mm}$ isoline for COSMO_CH. Positions and amounts of forecast precipitation maxima are indicated by crosses and their respective values. Gray shading indicates orography. The square delimits the $1^{\circ} \times 1^{\circ}$ area where averaged precipitation is computed. (b) time series of hourly mean precipitation rate (from 00:00 UTC 26 September, to 00:00 UTC 27 September 2007) over the square domain shown in (a). Lines refer to observations (blue) and various convection resolving models as indicated in the inlet. 
of the convective available potential energy (CAPE) computed upstream of the Lagoon (not shown) indicates that sensibly lower values of CAPE were simulated by COSMO_CH run, suggesting a possible reason for the remarkably smaller amount of precipitation of this model.

We suggest that a key role for the generation and maintenance of the MCS was played by the surface south-easterly flow that developed over the Adriatic Sea, in the form of a LLJ, induced mainly by the synoptic scale environment. Differences in the simulation of the dynamical and thermodynamic properties associated with this LLJ and its interaction with other currents, especially the north-easterly flow south of the Alps, implied significant differences in precipitation amount and location.

\section{MOLOCH experiments}

A large number of MOLOCH a posteriori forecast experiments were performed with the aim of assessing the sensitivity of the forecasts to various factors. In these experiments, the horizontal resolution was the same as for the D-PHASE $(2.2 \mathrm{~km})$, but in a slightly smaller domain, centred over the area of interest. The MOLOCH runs considered here, always starting at 01:00 UTC of 26 September, were nested into BOLAM runs (as in the operational suite) initiated at different times.

In order to evaluate heuristically the forecast uncertainty associated with the initial and boundary conditions, various experiments were run starting with ECMWF analyses at 00:00 and 12:00 UTC of 25 September and 00:00 UTC of 26 September, and GFS analyses at 00:00 UTC of 25 and 26 September, respectively. The boundary conditions were supplied every $3 \mathrm{~h}$ by the corresponding global forecasts. The two simulations starting at 00:00 UTC of 25 September produced the best forecasts, displaying similar intense precipitation maxima (well above $200 \mathrm{~mm}$ in $12 \mathrm{~h}$ ) over or close to the Venice Lagoon. The GFS-based run, as for the operational D-PHASE forecasts, gave the best localization of the precipitation peak. All the other simulations initialized at later times produced weaker precipitation, with larger localization errors.

The position and intensity of the precipitation maxima obtained in the five experiments are synthetically sketched in Fig. 5, which shows also the model orography. Different colours indicate precipitation ranges: blue: $>200 \mathrm{~mm}$; red: 150-200 mm; yellow: $100-150 \mathrm{~mm}$. The position of the observed precipitation maximum is shown too. The blue circle, having a radius of $40 \mathrm{~km}$, encompasses all the precipitation maxima resulting also from other sensitivity experiments. The MCS developed in all the MOLOCH simulations within this blue circle.

Among the simulations considered here, one of the distinctive features that characterize the "successful" forecasts (in the sense that produce realistic amounts of precipitation)



Fig. 5. Position and intensity of precipitation maxima obtained using different global model initial conditions (see text). Each box indicates the value of max precipitation, the driving global model (GFS or European Centre-EC), and date (day) and time (UTC) of the initial condition. Location of observed max precipitation is indicated by the magenta arrow.

is related to the vertical penetration and degree of organization of the simulated MCS. The observed MCS was preceded by a multi-cellular stage, before developing into a V-shape structure (Fig. 1b). The MOLOCH forecast initialized with GFS analysis at 00:00 UTC of 25 September, which was the simulation displaying the best agreement with rainfall observations, reproduced both stages of development, that is the multi-cellular and the MCS stages. Maps of vertical velocity at $500 \mathrm{hPa}$ reveal scattered convection in the early morning of 26 September (not shown) turning into organized convection later. In particular, Fig. 6 shows the V-shape feature of the mid-high tropospheric updraft, closely reflecting the shape of the cloud top visible in Fig. 1b.

Model simulations showed that, although the MCS affected a flat area, the surrounding orography played a key role in determining a mesoscale environment favourable to its development. The MCS developed during a lee cyclogenesis process: at 00:00 UTC of 26 September, a distinct geopotential minimum is present over the Ligurian Sea, as indicated by mean sea level pressure analysis in Fig. 3a, also verified in the BOLAM model forecast. The lee cyclone circulation induced, together with the direct barrier effects of the Alps as well as of the Apennines and the Dinaric Alps, a strong low-level flow confluence/convergence over the area where severe convection was initiating. Over the Adriatic, a south-easterly LLJ advected warm and moist air, 


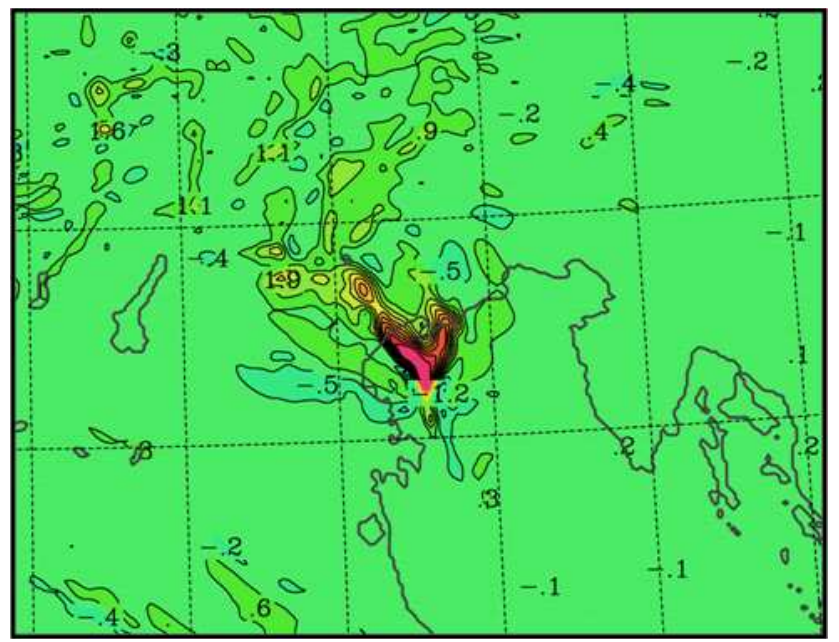

Fig. 6. Vertical velocity $(\mathrm{m} / \mathrm{s})$ at $500 \mathrm{hPa}$, forecast at 11:00 UTC, 26 September 2007 by MOLOCH_GFS. Red shading indicates upward motions. Contour interval $0.5 \mathrm{~m} / \mathrm{s}$.

while a north-easterly cold flow (partly a barrier wind) was present more to the north, over the Veneto plains. In the case the BOLAM run was performed after the model orography height was arbitrarily reduced to one fourth of its original amplitude, the lee cyclone and related convergence were suppressed (not shown), the cold front moved smoothly to the southeast and severe convection did not develop in such experiment.

Finally, a number of additional experiments were performed in order to investigate the sensitivity to the model chain set up (including the intermediate BOLAM model), model parameters and physical and dynamical schemes. A detailed description of all these experiments is out of the scope of the present paper. However, it is worth noting that results were sensitive to the convective parameterization scheme applied in the lower resolution model, the extension of the inner domain, the time at which the fine resolution model was initiated, and the spatial resolution. In almost all cases, the MCS developed in the model within the area surrounded by the blue circle depicted in Fig. 5 .

\section{MM5-WRF experiments}

Several simulations were performed also using WRF (Skamarock et al., 2005) and MM5 (Grell et al., 1995) convection resolving models, in order to investigate the mechanisms responsible for the flood and to test the predictability of the event in a multi-model approach, complementing the previous analysis undertaken with MOLOCH. The WRF set up included two two-way nested domains while three two-way nested domains were used in MM5 runs. Different global forecasts (GFS and ECMWF) were used as initial and boundary conditions, and different convective schemes -
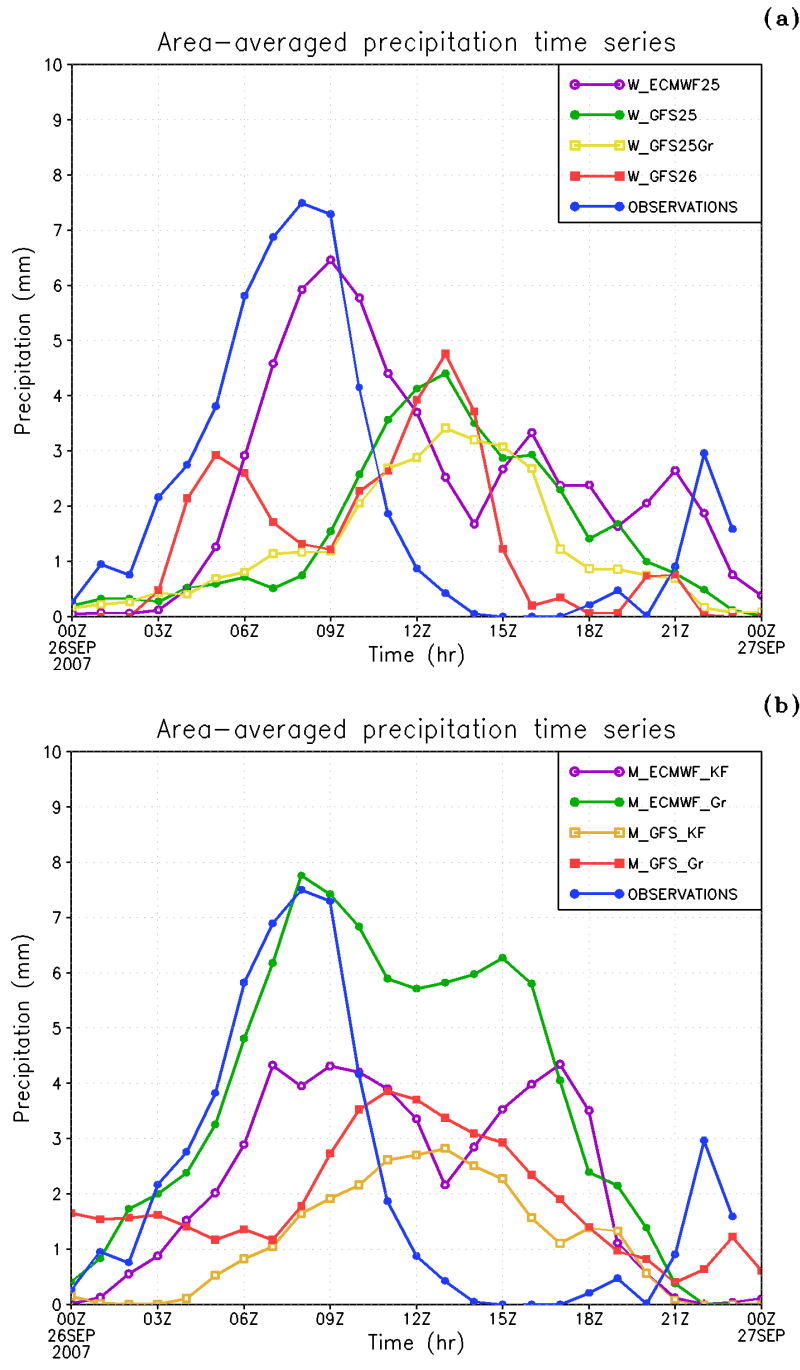

(b)

Fig. 7. As in Fig. 4b, but for WRF (a) and MM5 (b) experiments.

Grell (Grell, 1993), Kain-Fritsch (Kain and Fritsch, 1990, in MM5; Kain, 2004, in WRF) - were activated except in the highest resolution domains. Further details on the different experiments are shown in Table 2.

Figure $7 \mathrm{a}$ and $\mathrm{b}$ presents the simulation results in terms of precipitation time series, averaged over the area sketched in Fig. 4a. WRF produced a satisfactory forecast only when initialized with ECMWF data (Fig. 7a): the rainfall peak was well in agreement with the observations in terms of both amount and timing, although the precipitation maximum was located just off shore, about $50 \mathrm{~km}$ away from the exact location (not shown). While WRF forecasts did not display remarkable sensitivity to the convective parameterization schemes employed in the lower resolution domains, MM5 showed strong sensitivity to this factor. In general, when the Grell scheme was used, MM5 resulted in wetter forecasts. In MM5 the best performances were also obtained when the model was driven by ECMWF data (Fig. 7b). 
Table 2. Main characteristics of WRF and MM5 experiments.

\begin{tabular}{lllll}
\hline Experiment & Model & Initial/boundary conditions & $\begin{array}{l}\text { Resolution of nested } \\
\text { models }(\mathrm{km})\end{array}$ & $\begin{array}{l}\text { Convective parameterization } \\
\text { scheme }\end{array}$ \\
\hline W_ECMWF25 & WRF & ECMWF, 00:00 UTC, 25 Sep & $16-4$ & Kain-Fritsch \\
W_GFS25 & WRF & GFS, 00:00 UTC, 25 Sep & $16-4$ & Kain-Fritsch \\
W_GFS26 & WRF & GFS, 00:00 UTC, 26 Sep & $16-4$ & Kain-Fritsch \\
W_GFS25Gr & WRF & GFS, 00:00 UTC, 25 Sep & $16-4$ & Grell \\
M_ECMWF_KF & MM5 & ECMWF, 00:00 UTC, 25 Sep & $22.5-7.5-2.5$ & Kain-Fritsch \\
M_ECMWF_Gr & MM5 & ECMWF, 00:00 UTC, 25 Sep & $22.5-7.5-2.5$ & Grell \\
M_GFS_KF & MM5 & GFS, 00:00 UTC, 25 Sep & $22.5-7.5-2.5$ & Kain-Fritsch \\
M_GFS_Gr & MM5 & GFS, 00:00 UTC, 25 Sep & $22.5-7.5-2.5$ & Grell \\
\hline
\end{tabular}

In particular, the run initialized with the ECMWF analysis at 00:00 UTC of 25 September, implementing the Grell scheme, did forecast a rainfall maximum above $400 \mathrm{~mm}$ in $12 \mathrm{~h}$ in the area of Venice Lagoon, in very good agreement with the observation. However, the predicted precipitation went on until late afternoon of 26 September, producing a remarkable overestimation.

As for the MOLOCH cases (see Sect. 4), in the above simulations the major mesoscale feature related to the triggering and maintenance of convection is the confluence of the lowlevel south-easterly wind with the north-easterly flow. The value of the adimensional mountain height (inverse Froude number) $H=h N / U$ (where $h$ is the mountain height, $N$ the Brunt-Väisälä frequency, $U$ the environmental wind speed) was computed, at 00:00 UTC of 26 September, in the lower $1.5 \mathrm{~km}$ over the region of easterly flow near the Alps (see Fig. 8 for the location) for all the WRF simulations. The resulting values of $H \approx 2$ is consistent with the occurrence of a "flow-around" regime (Miglietta and Buzzi, 2001), that is, a blocking effect caused by the Alps. This argument suggests that the north-easterly flow, originating just before the beginning of the convective event, was a barrier wind associated with the main south-easterly flow more upstream (Fig. 8). The low level wind pattern characterized by the north-easterly airflow converging over the Veneto coastal region with the south-easterly flow prevailing over the Adriatic appears to be a distinctive feature of precipitation episodes in this area under large scale meridional flow conditions (Buzzi, 2004; Monai et al., 2006).

\section{Conclusions}

The analysis of an intense MCS that affected the Venice Lagoon area during the morning of 26 September 2007 with severe precipitation and flood has provided the opportunity to evaluate the performance of high resolution, convection resolving models, some of them employed for real-time forecasting during the MAP D-PHASE operational period. Diagnosis of the various simulations has allowed to investigate the

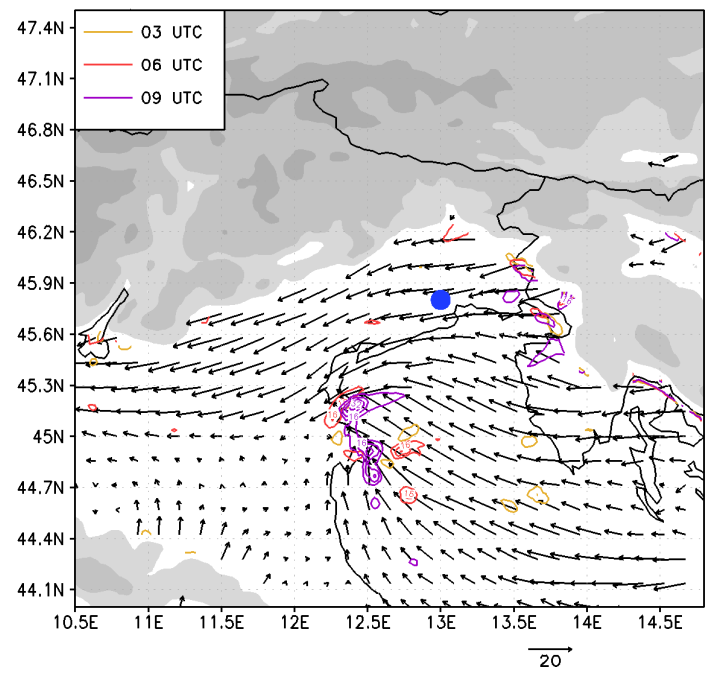

Fig. 8. WRF forecast (W_ECMWF25 experiment): $950 \mathrm{hPa}$ wind (vectors; m/s) at 09:00 UTC, 26 September 2007 and wind convergence (contour interval $8 \times 10^{-4} \mathrm{~s}^{-1}$ ) at 03:00, 06:00 and 09:00 UTC, as indicated in the inlet. The blue point denotes the location where the Froude number was evaluated.

physical mechanisms responsible for the MCS development and to evaluate to what extent organized convection can be predicted by convection resolving models. Simulations highlighted the importance of the larger scale features and of their interaction with orography (lee cyclone development), determining the low-level circulation affecting the area. The most relevant characteristic was the convergence of south-easterly moist and unstable wind from the Adriatic Sea and northeasterly flow. We suggest that the latter flow was initially due to a barrier effect exerted by the Alps on the oncoming south-easterly flow and later in the morning of 26 September cold air crossing eastern Alps reinforced this barrier flow. The above results indicate that, in spite of the large variability among models and even for the same model initialized with different large-scale conditions, forecasting severe convective events in advance of one day or so, with sufficient space 
and time accuracy for a suitable alert procedure, may be feasible in cases in which convection is embedded in mesoscale flows with some degree of predictability. Also in the similar case of Montserrat, the degree of predictability of the event, using limited-area meteorological models, resulted to be high (Mariani et al., 2005). This is consistent with the recent finding of Weisman et al. (2008), regarding the forecast application of the WRF model over the North America. In fact they concluded that "The relative success in forecasting seemingly unpredictable phenomenon such as convection out to $36 \mathrm{~h}$ seems most directly related to its strong connection to identifiable and more predictable synoptic or subsynoptic features, which establish the mesoscale environment favourable for the convection as well as serving as the primary triggering agent".

Acknowledgements. The authors are grateful to ARPA Veneto, Comune di Venezia and ISMAR-CNR for having provided local observational data.

Edited by: S. Michaelides, K. Savvidou, and F. Tymvios Reviewed by: two anonymous referees

\section{References}

Anquetin, S., Yates, E., Ducrocq, V., Samouillan, S., Chancibault, K., Davolio, S., Accadia, C., Casaioli, M., Mariani, S., Ficca, G., Gozzini, B., Pasi, F., Pasqui, M., Garcia, A., Martorell, M., Romero, R., and Chessa, P.: The 8 and 9 September 2002 flash flood event in France: a model intercomparison, Nat. Hazards Earth Syst. Sci., 5, 741-754, 2005,

http://www.nat-hazards-earth-syst-sci.net/5/741/2005/.

Bouttier, F. and Roulet, B.: Arome, the new high resolution model of Meteo-France, The European forecaster - Newsletter of the WGCEF, printed by: Meteo-France, 13, 27-30, 2008.

Buzzi, A.: Heavy precipitation and Alpine orography, Proc. of the International Workshop on timely warnings of heavy precipitation episodes and flash floods, Ljubljana, 12 pp., 21-22 October 2004.

Daley, R.: Atmospheric Data Analysis, Cambridge University Press, Cambridge, 480 pp., 1991.

Fischer, C., Montmerle, T., Berre, L., Auger, L., and Stephanescu, S. E.: An overview of the variational assimilation in the ALADIN/FRANCE NWP system, Q. J. Roy. Meteor. Soc., 131, 3477-3492, 2005.

Grell, G. A.: Prognostic evaluation of assumptions used by cumulus parameterization, Mon. Weather Rev., 121, 764-787, 1993.

Grell, G. A., Dudhia, J., and Stauffer, D.: A description of the fifthgeneration Penn State/NCAR mesoscale model (MM5), NCAR Tech. Notes, 398+STR, 117 pp., 1995.

Hohenegger, C. and Schär, C.: Atmospheric predictability at synoptic versus cloud-resolving scales, B. Am. Meteorol. Soc., 88, 1783-1793, 2007.
Kain, J. S.: The Kain-Fritsch convective parameterization scheme: an update, J. Appl. Meteorol., 43, 170-181, 2004.

Kain, J. S. and Fritsch, J. M.: A one-dimensional entraining/detraining plume model and its application in convective parameterization, J. Atmos. Sci., 47, 2784-2802, 1990.

Malguzzi, P., Grossi, G., Buzzi, A., Ranzi, R., and Buizza, R.: The 1996 "century" flood in Italy. A meteorological and hydrological revisitation, J. Geophys. Res., 111, D24106, doi:10.129/2006JD007111, 2006.

Mariani, S., Casaioli, M., Accadia, C., Llasat, M. C., Pasi, F., Davolio, S., Elementi, M., Ficca, G., and Romero, R.: A limited area model intercomparison on the "Montserrat-2000" flashflood event using statistical and deterministic methods, Nat. Hazards Earth Syst. Sci., 5, 565-581, 2005,

http://www.nat-hazards-earth-syst-sci.net/5/565/2005/.

Miglietta, M. M. and Buzzi, A.: A numerical study of moist stratified flows over isolated topography, Tellus A, 53, 481-499, doi:10.1111/j.1600-0870.2001.00481.x, 2001.

Monai, M., Rossa, A. M., and Bonan, A. C.: Partitioning of snowy and rainy precipitation in a case of a north Adriatic frontal passage, Adv. Geosci., 7, 279-284, 2006, http://www.adv-geosci.net/7/279/2006/.

Richard, E., Buzzi, A., and Zängl, G.: Quantitative precipitation forecasting in the Alps: the advances achieved by the Mesoscale Alpine Programme, Q. J. Roy. Meteor. Soc., 133, 831-846, 2007.

Rotach, M. W., Ambrosetti, P., Ament, F., Appenzeller, C., Arpagaus, M., Bauer, H-S., Bouttier, F., Buzzi, A., Corazza, M., Davolio, S., Denhard, M., Dorninger, M., Fontannaz, L., Frick, J., Fundel, F., Germann, U., Gorgas, T., Hegg, C., Hering, A., Keil, C., Liniger, M. A., Marsigli, C., McTaggart-Cowan, R., Montani, A., Mylne, K., Ranzi, R., Richard, E., Rossa, A., Santos-Muňoz, D., Schär, C., Seity, Y., Staudinger, M., Stoll, M., Volkert, H., Walser, A., Wang, Y., Werhahn, J., Wulfmeyer, V., and Zappa, M.: MAP D-PHASE: real-time demonstration of weather forecast quality in the Alpine region, B. Am. Meteorol. Soc., in press, October 2009.

Schraff, C. H.: Mesoscale data assimilation and prediction of low stratus in the Alpine region, Meteorol. Atmos. Phys., 64, 21-50, 1997.

Skamarock, W. C., Klemp, J. B., Dudhia, J., Gill, D. O., Barker, D. M., Wang, W., and Powers, J. G.: A description of the Advance Research WRF Version 2, NCAR Tech. Notes, 468+STR, 88 pp., 2005.

Weisman, M. L., Davies, C., Wang, W., Manning, K. W., and Klemp, J. B.: Experiences with 0-36-h explicit convective forecasts with the WRF-ARW model, Weather Forecast., 23, 407437, 2008.

Zampieri, M., Malguzzi, P., and Buzzi, A.: Sensitivity of quantitative precipitation forecasts to boundary layer parameterization: a flash flood case study in the Western Mediterranean, Nat. Hazards Earth Syst. Sci., 5, 603-612, 2005, http://www.nat-hazards-earth-syst-sci.net/5/603/2005/. 